\title{
Comparison of the effect of semi-rigid ankle bracing on performance among injured v. non-injured adolescent female hockey players
}

T J Ellapen, PhD; N Acampora, BSps Hons (Biokinetics); S Dawson, BSps Hons (Biokinetics); J Arling, BSps Hons (Biokinetics); C van Niekerk, BSps Hons (Biokinetics); H J van Heerden, D Phil

Department of Biokinetics, Exercise and Leisure Sciences, School of Health Science, University of KwaZulu-Natal, Westville, South Africa

Corresponding author: T J Ellapen (tellapen1@yahoo.com)

Objective. To determine the comparative proprioceptive performance of injured v. non-injured adolescent female hockey players wearing an ankle brace.

Methods. Data were collected from 100 high school players who belonged to the Highway Secondary School Hockey League, KwaZuluNatal, via voluntary parental informed consent and player assent. Players completed an injury questionnaire probing the prevalence and nature of hockey injuries (March - August 2013). Subsequently, players completed a Biodex proprioceptive test with and without an ankle brace. Probability was set at $p \leq 0.05$.

Results. Twenty-two players sustained ankle injuries within the 6-month study period $(p<0.001)$. Injured players performed similarly without bracing (right anterior posterior index (RAPI) 2.8 (standard deviation (SD) 0.9); right medial lateral index (RMLI) 1.9 (0.7); left anterior posterior index (LAPI) 2.7 (0.9); left medial lateral index (LMLI) 1.7 (0.6)) compared with bracing (RAPI 2.7 (1.4); RMLI 1.8 (0.6); LAPI 2.6 (1.0); LMLI $1.5(0.6))(p>0.05)$. However, bracing improved the ankle stability of the non-injured group (RAPI 2.2 (0.8); RMLI 1.5 (0.5); LAPI 2.4 (0.9); RMLI 1.5 (0.5)) compared with their performance without a brace (RAPI 2.5 (1.0); RMLI 1.8 (0.8); LAPI 2.8 (1.1); LMLI $1.8(0.6))(p<0.05)$.

Conclusion. Ankle bracing did not enhance the stability of injured ankles. However, ankle bracing has an ergogenic effect that enhances the stability of healthy ankles.

S Afr J SM 2014;26(3):73-76. DOI:10.7196/SAJSM.517

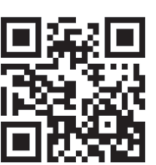

Dynamic proprioception is an integral motor component of hockey. ${ }^{[1,2]}$ The most common field hockey injury is inversion ankle sprains, the injury mechanism of which has been associated with poor proprioception. ${ }^{[1,2]}$ Poor dynamic proprioception among hockey players often leads to ankle injuries, because the proprioceptors do not send impulses to the central nervous system quickly to ensure that the efferent neurons innervate the appropriate muscles to maintain joint stability. ${ }^{[2,3]}$ Predisposing factors that are attributed to field hockey injuries include frequency of hockey played, rapid, repetitive rotational movements of the ankle joint, and direct physical trauma inflicted by players on each other during tackles and collisions. ${ }^{[2,3]}$ The pathomechanics of the common lateral ankle sprain among hockey players is rapid, uncontrolled excessive inversion and plantar flexion of the rear foot on the tibia. ${ }^{[2,3]}$ This abrupt change in kinesiology of the talocrural joint sometimes exceeds the elastic property of the static restraints of the anterior and posterior talofibular and calcaneofibular ligaments. ${ }^{[2,3]}$

Prophylactic ankle bracing is prescribed in the management of ankle injuries during the return of previously injured hockey players into the game. ${ }^{[4]}$ The success of prophylactic ankle bracing as an effective rehabilitative device is controversial. ${ }^{[4-7]}$ Olmstead et al. ${ }^{[4]}$ and Sharpe et al. ${ }^{[5]}$ suggest that ankle bracing enhances the stability of the ankle by increasing the mechanical static restraints of the anterior and posterior talofibular and calcaneofibular ligaments, which limits excessive plantar flexion, inversion and eversion. ${ }^{[4,5]}$ This enhanced mechanical static restraint of the prophylactic brace serves as a protective mechanism to limit inversion ankle sprains. ${ }^{[4,5]}$ However, Anderson et al. ${ }^{[6]}$ and Bot and Van Mechelen ${ }^{[7]}$ reported that ankle bracing reduces the functional proprioceptive ability of the ankle joint owing to the limited movement in the frontal and transverse planes. Bracing limits the range of movement at the talocrural joint in the frontal and transverse planes, but increases the risk of high ankle sprains at the distal tibofibular joint, as well as fractures at the distal tibia and lateral collateral ligament sprains of the knee. ${ }^{[6,7]}$ Prolonged prophylactic ankle bracing decreases the neural firing of the proprioceptors, which delay the activation of the ankle evertors, resulting in recurring ankle inversion sprains. ${ }^{[6,7]}$

The literature has examined the efficacy of ankle bracing on proprioception in soccer, basketball and athletic populations, with the findings being applied to hockey. ${ }^{[4,5]}$ Soccer, basketball and hockey share common motor skills, which require players to sprint and make sudden changes in the direction around their opponents to gain advantage play. ${ }^{[1]}$ Due to the similarities in motor skills among these sports and the absence of literature examining the effect of prophylactic ankle bracing on the proprioception of hockey players specifically, injured hockey players started to use these braces on their return to play. ${ }^{[4]}$ The objective of this study was to determine the effect of ankle bracing on the proprioception 
of injured v. non-injured adolescent female hockey players in the frontal and sagittal planes, using the Biodex balance system 3 .

\section{Method}

A total of 100 adolescent female hockey players voluntarily participated in a controlled, randomised, observational pre-test posttest crossover investigation, with parental informed consent. Ethical approval was obtained from the School of Health Science Research Committee, University of KwaZuluNatal (SHSEC010/13). Inclusion criteria were female players who were affiliated to the Highway Secondary School Hockey League of KwaZulu-Natal, within the age range of 13 - 16 years. Five schools participate in this league, each fielding two first teams (under-14 and -16 year age divisions). Each school team has 14 players, totalling 28 players per school. Therefore, the total number of players in the league specific to the age strata being studied is 140 players. Players were requested to indicate only hockey injuries sustained in the last 6 months (March - August 2013), and not injuries contracted from other sport and/or recreational activities. Forty players were excluded because they sustained injuries while participating in recreational activities and sport other than hockey. Injured hockey players were not injured during data collection because data were collected after the hockey playing season, during September 2013. The sample was $71.4 \%$ representative of the total number of league players, which is higher than the $30 \%$ statistical rule of thumb needed to indicate pertinent relationships between the independent and dependent variables of the cohort. ${ }^{[8]}$

An interviewer - a graduate student who was thoroughly grounded in the research protocol and fluent in English, Afrikaans and isiZulu - administered a questionnaire to all players, whereafter Biodex dynamic proprioception pre- and post-testing occurred. The players' history of hockey injuries was obtained by using an injury questionnaire adapted from Ellapen et al. ${ }^{\left[{ }^{[3]}\right.}$ and Kee and Seo. ${ }^{[9]}$ In the current study, an injury was defined as a sensation of distress or agony that prevented the hockey player from physical activity for a minimum period of $48 \mathrm{~h}$ due to a specific predisposing mechanism of injury (adapted from Van Heerden ${ }^{[10]}$ ). Pain was questioned because it is a discernible symptom of musculoskeletal and/or ligamentous injuries.
The injury questionnaire was divided into five parts: demographic details, anatomical site of the injury, severity of the associated pain according to the Kee and Seo ${ }^{[9]}$ Pain Rating Scale, the type of injury symptoms (dull aching, discomfort, sharp, pins and needles, numbness, burning and radiating) and the predisposing mechanism of the injury in accordance with Hagglund et al.'s ${ }^{[1]}$ definition of sport injuries. Hagglund et al. reported that the fundamental problem concerning international epidemiological sport investigations is the inconsistent definition of musculoskeletal injury. ${ }^{[11]}$ They proposed that the prevalence of musculoskeletal injury can be established if the following has been documented: anatomical site of musculoskeletal pain, type of musculoskeletal pain sustained and severity of pain measured by a validated pain rating scale. ${ }^{[1]}$ The questionnaire was translated into English, isiZulu and Afrikaans.

\section{Biodex dynamic proprioception test}

After the interview, the players were randomly allocated into either a control or experimental group through the use of a table of random numbers (50 players in each). The use of control and experimental groups was to blind the identity of the ankleinjured players and to prevent bias when interpreting the proprioception results. The difference between the groups was the use of the semi-rigid prophylactic ankle brace, which was worn by the experimental group. The use of a semi-rigid ankle brace served as an acute intervention, thus creating different scenarios under which the experimental and control groups were tested. After the pretest, the participants crossed over into their respective groups, to complete their dynamic proprioception post-test (Fig. 1). The terms

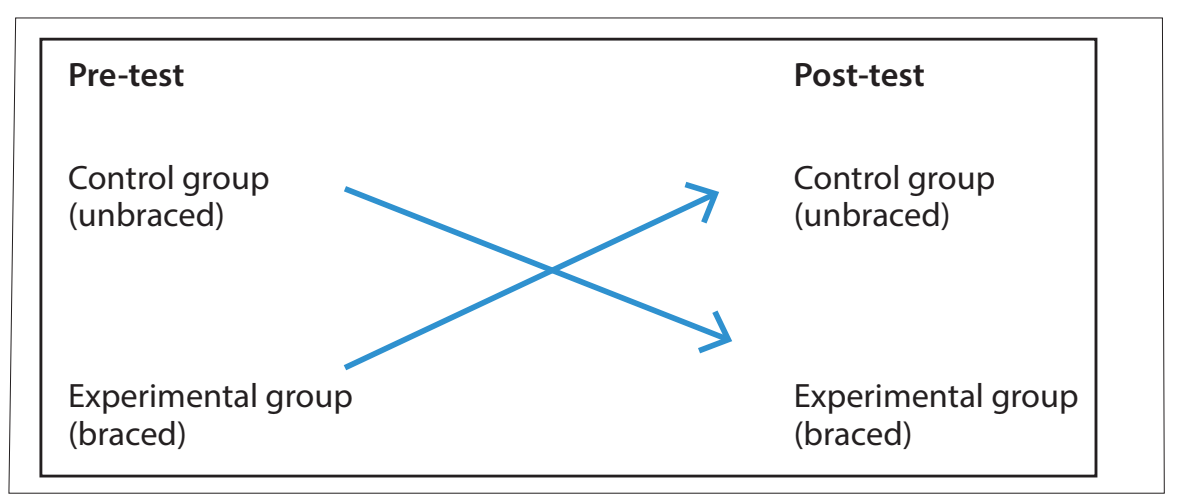

Fig. 1. Visual description of the pre-test post-test cross-over. 'braced' and 'unbraced' refer to the experimental group and control group, respectively. All 100 players underwent a Biodex dynamic proprioception test (unilateral dynamic limits of stability) that measured their proprioception in the frontal and sagittal planes. The test lasted 60 seconds per leg (adapted from Finn's ${ }^{[12]}$ protocol). During the course of this test, the stability of the balance platform was designed to become less stable, decreasing from eight-pin stability to one-pin stability. The anterior posterior index (API) measures the ankle stability in the sagittal plane, while the medial lateral index (MLI) measures the frontal plane stability, with a high stability index indicating poor stability. ${ }^{[12]}$

\section{Statistical analyses}

The cohort was described using mode, means, frequencies and percentages. Data were further analysed using inferential statistics, namely $\chi^{2}$ tests, two-tail $t$-tests adjusted for equal variance and the Levene's test to assess the homogeneity variance. The $\chi^{2}$ statistical test compares the counts or tallies of the categorical observed and expected results. A two-tailed $t$-test assumes that the difference between the two means could favour either group. Levene's test is an inferential statistic used to assess the equality of variances for two groups. If the resulting $p$-value of Levene's test is less than the typical 0.05 value, the obtained differences in sample variances are unlikely to have occurred based on random sampling from a population with equal variances. The Levene's test indicated equal variance $(p>0.05)$. The alpha level was set at $a<0.05$.

\section{Results}

The cohort was stratified into ankle-injured and non-injured players using their injury profile. The results are presented in the 
following categories: demographic details with respect to their injury profile, anatomical site of injury, severity of the associated pain and the type of injury symptoms. The participants' weekly training profile history was established to determine whether it was a predisposing factor to their ankle injuries. The dynamic proprioceptive results are also presented.

Of the 100 players, 22 sustained ankle injuries within the previous 6 months (March August 2013) $(p<0.001)$; these players did not sustain injuries to other anatomical sites. Some of the 78 players who did not sustain ankle injuries, did sustained injuries at other anatomical sites (shoulder, hand and back) that could have influenced their dynamic proprioception (which is a limitation of the study). The age, body mass and stature of the ankle-injured and non-injured players are presented in Table 1. The mechanisms of the ankle injuries were colliding with another player (28\%), being struck with a ball (25\%) or a hockey stick (25\%) and rapid rotation change in direction (22\%).

The Kee and Seo ${ }^{[9]}$ Pain Rating Scale (range 1 - 5) was used to determine the severity of the pain symptoms experienced when the ankle was injured. A score of 4 (severe pain) was rated the most prevalent $(55 \%)$ followed by 3 (moderate pain) (36\%) and 2 (mild pain) (9\%). The symptoms of ankle injuries reported were swelling (30\%), then sharp pain (19\%), dull aching pain (18\%), radiating pain (16\%), pins and needles (7\%) and numbness (5\%) $(p<0.0001)$. A study limitation was the lack of a comprehensive musculoskeletal injury appraisal to determine causes of the pain.

The training profile of the ankle-injured and non-injured players for the previous 12 months showed comparable months of hockey played and duration per session, suggesting that these factors were not predisposing factors to injury (Table 2). Although there were variations in performance between the injured and non-injured players during the unbraced phase, they were not statistically significant (Table 3). Similarly, the braced proprioception scores varied but not significantly so, except for the non-injured players' better right API performance (Table 4). The semi-rigid ankle brace was not an effective rehabilitative device, as shown by the ankle-injured unbraced and braced performance (Table 5).

Table 6 provides evidence that the semirigid brace is an effective ergogenic aid that enhances the proprioception of non-injured ankles. The braced performance of the non-

Table 1. Demographic measures of injured and non-injured players

\begin{tabular}{llll}
\hline Variables, mean $(\mathrm{SD})$ & Injured $(\boldsymbol{n}=\mathbf{2 2})$ & Non-injured $(\boldsymbol{n}=\mathbf{7 8})$ & $\boldsymbol{p}$-value \\
\hline Age (years) & $14.8(1.2)$ & $14.8(1.1)$ & 0.85 \\
Body mass (kg) & $59.1(8.9)$ & $55.2(7.0)$ & 0.03 \\
Stature (m) & $1.6(0.05)$ & $1.59(0.06)$ & 0.55 \\
SD = standard deviation. & & &
\end{tabular}

Table 2. Weekly training profile of injured and non-injured players

\begin{tabular}{llll}
\hline Variables, mean $(\mathrm{SD})$ & Injured $(\boldsymbol{n}=\mathbf{2 2})$ & Non-injured $(\boldsymbol{n}=\mathbf{7 8})$ & $\boldsymbol{p}$-value \\
\hline Months playing hockey & $8.4(3.3)$ & $6.8(3.5)$ & 0.06 \\
Sessions/week & $3.6(1.2)$ & $3.0(1.4)$ & 0.05 \\
Duration/session (minutes) & $114.5(0.5)$ & $118.4(1.6)$ & 0.82 \\
SD = standard deviation. & & &
\end{tabular}

Table 3. Comparison of the injured v. non-injured players Biodex dynamic proprioception during the unbraced phase

\begin{tabular}{llll}
\hline Dynamic measures, mean $(\mathrm{SD})$ & Injured $(\boldsymbol{n}=\mathbf{2 2})$ & Non-injured $(\boldsymbol{n}=\mathbf{7 8})$ & $\boldsymbol{p}$-value \\
\hline Right API & $2.8(0.9)$ & $2.5(1.0)$ & 0.31 \\
Right MLI & $1.9(0.7)$ & $1.8(0.8)$ & 0.68 \\
Left API & $2.7(0.9)$ & $2.8(1.1)$ & 0.85 \\
Left MLI & $1.7(0.6)$ & $1.8(0.6)$ & 0.53
\end{tabular}

$\mathrm{SD}=$ standard deviation; $\mathrm{API}=$ anterior posterior index; $\mathrm{MLI}=$ medial lateral index .

Table 4. Comparison of the injured v. non-injured groups Biodex dynamic proprioception during the braced phase

\begin{tabular}{llll}
\hline Dynamic measures, mean $(\mathrm{SD})$ & Injured $(\boldsymbol{n}=\mathbf{2 2})$ & Non-injured $(\boldsymbol{n}=\mathbf{7 8})$ & $\boldsymbol{p}$-value \\
\hline Right API & $2.7(1.4)$ & $2.5(1.0)$ & 0.03 \\
Right MLI & $1.8(0.6)$ & $1.8(0.8)$ & 0.06 \\
Left API & $2.6(1.0)$ & $2.8(1.1)$ & 0.40 \\
Left MLI & $1.5(0.6)$ & $1.8(0.6)$ & 0.97
\end{tabular}

$\mathrm{SD}=$ standard deviation; $\mathrm{API}=$ anterior posterior index; $\mathrm{MLI}=$ medial lateral index .

Table 5. Comparison of the injured group's unbraced v. braced dynamic proprioception $(n=22)$

\begin{tabular}{llll}
\hline Dynamic measures, mean (SD) & Unbraced & Braced & $\boldsymbol{p}$-value \\
\hline Right API & $2.8(0.9)$ & $2.7(1.4)$ & 0.87 \\
Right MLI & $1.9(0.7)$ & $1.8(0.6)$ & 0.60 \\
Left API & $2.7(0.9)$ & $2.6(1.0)$ & 0.67 \\
Left MLI & $1.7(0.6)$ & $1.5(0.6)$ & 0.47 \\
SD = standard deviation; API = anterior posterior index; MLI = medial lateral index. & &
\end{tabular}

injured players was significantly better than their unbraced performance.

\section{Discussion}

The results are discussed here with respect to injury profile, dynamic proprioception performance and demographic details. The weekly training profile is discussed within the injury profile, as a predisposing mechanism of ankle injuries. There were 22 players (22\%) who sustained ankle injuries during the previous 6 months, which is similar to previous hockey 
Table 6. Comparison of the non-injured group's unbraced $v$. braced dynamic proprioception $(n=78)$

\begin{tabular}{llll}
\hline Dynamic measures, mean (SD) & Unbraced & Braced & $\boldsymbol{p}$-value \\
\hline Right API & $2.5(1.0)$ & $2.2(0.8)$ & 0.02 \\
Right MLI & $1.8(0.8)$ & $1.5(0.5)$ & 0.01 \\
Left API & $2.8(1.1)$ & $2.4(0.9)$ & 0.04 \\
Left MLI & $1.8(0.6)$ & $1.5(0.5)$ & 0.01 \\
SD = standard deviation; API = anterior posterior index; MLI = medial lateral index. & &
\end{tabular}

epidemiological investigations, indicating the prolific occurrence of ankle injuries. ${ }^{[2,3]}$

\section{Injury profile}

The mechanisms of the ankle injuries were colliding with another player, being struck with a ball or a hockey stick and rapid rotation change in direction, which is comparable with the findings of Naicker $e t$ al. ${ }^{[2]}$ Naicker $e t$ al. postulated that rapid rotational movements during play move the ankle into plantar flexion and inversion, which exceeds the plastic properties of the lateral ligaments, resulting in tearing. ${ }^{[2]}$ Gallagher ${ }^{[1]}$ reported that hockey players often sprint (with possession of the ball), and make sudden changes in direction of movement around their opponents to gain advantage play, which increases the risk of musculoskeletal injury and pain. The injured players completed more hockey training sessions per week than non-injured players; therefore we theorise that the additional hockey training sessions per week increased their risk of injury. Ellapen et al. ${ }^{[3]}$ have reported that increased frequency of hockey training sessions per week increases the risk of ankle injuries.

\section{Proprioceptive performance}

The injured and non-injured groups' dynamic proprioceptive performance during the unbraced phase did not differ significantly and was comparable. The injured group's braced right API was significantly higher than that of the non-injured group, suggesting that the ankle bracing did not enhance the stability of the injured ankle joint in the sagittal plane. The evidence from the braced phase suggests that semi-rigid ankle bracing does not enhance ankle proprioception, but could impair performance. Hockey players who possess poor dynamic proprioception often sustain ankle injuries. ${ }^{[2]}$

The comparison of the unbraced and braced dynamic proprioceptive performance of the injured group indicates no significant differ- ence. This evidence suggests that prophylactic bracing did not improve ankle proprioception, refuting the findings of Olmstead et al. ${ }^{[4]}$ and Sharpe et al..$^{[5]}$ It is postulated that the prophylactic brace did not provide adequate mechanical restraint to the weakened anterior and posterior talofibular and calcaneofibular ligaments, thereby not stabilising the ankle joint, and did not improve the neural firing and subsequent evertor activation of the injured ankle's proprioceptors, which is similar to the theorisation of Anderson et al. ${ }^{[6]}$ and Bot and Van Mechelen. ${ }^{[7]}$

Bracing did enhance the performance of healthy ankles, which is similar to the findings of Jerosch, Bocchinfuso et al. and Gross et al. ${ }^{[13-15]}$ This evidence suggests that ankle bracing has an ergogenic effect on healthy ankle proprioception. Comparative analyses of the braced proprioceptive stability indices (API and MLI) of the non-injured group falls within the age-matched proprioception normative range $(0.8-2.2){ }^{[12]}$ Prophylactic ankle bracing seems to enhance the talocrural joint's congruency and stability while simultaneously allowing functional movement in

\section{Demographic measures}

The age and stature of the injured and noninjured players did not differ significantly, suggesting that these factors did not predispose the players to ankle injuries. However, the injured group was heavier than the noninjured group. The association of the increased body mass and occurrence of ankle injuries among hockey players has not been established in previous studies. It is theorised that the injured players became heavier during their injury period because of their inability to train. Future investigations should determine the validity of this, as it poses a study limitation.

\section{Conclusion}

Our results indicated that prophylactic semi-rigid ankle bracing is not an effective the frontal and transverse planes. rehabilitative management device for ankle injuries. However, it is an effective ergogenic aid among non-injured players. Future research should be conducted among adult professional and elite players to validate the findings of this study and to better understand the ergogenic effect of semirigid ankle bracing on non-injured ankles. These findings can assist hockey coaches, players and parents to become aware of the advantages and disadvantages of wearing semi-rigid ankle braces.

\section{References}

1. Gallagher D. Top women hockey teams visit South Africa. 2010. http://www.hockeysouthafrica.com (accessed 10 August 2010)

2. Naicker M, McLean M, Esterhuizen TM, Peters-Futre EM. Poor peak dorsiflexor torque associated with incidence of ankle injury in elite field female hockey players. J Sci Med Sport 2007;10(6):363-371. [http:// dx.doi.org/10.1016/j.jsams.2006.11.007]

3. Ellapen TJ, Abrahams S, Desai FA, Narsigan S, Van Heerden HJ. Prevalence of musculoskeletal pain among South African female senior national hockey players. Advances in Rehabilitation 2011;25(2); 27-31. [http://dx.doi.org/10.2478/rehab-2013-0007]

4. Olmstead LC, Vela LI, Denegar, CR, Hertel J. Prophylactic ankle taping and bracing: A numbersneeded to treat and cost benefit analysis. J Athl Train 2004;39(1):95-100.

5. Sharpe SR, Knapik J, Jones B. Ankle braces effectively reduce the recurrence of ankle sprains among female soccer players. J Athl Train 1997;32(1):21-24.

6. Anderson DL, Sanderson DJ, Hennig EM. The role of non-rigid ankle bracing in limiting ankle inversion. Clin J Sport Med 1995;5(1):18-24. [http://dx.doi. org/10.1097/00042752-199501000-00004]

7. Bot SDM, Van Mechelen W. The effect of ankle bracing on athletic performance. Sports Med 1999;27(3):171-178.

8. Terre-Blanche M, Durrheim K, Painter D. Research in Practice. Cape Town: University of Cape Town Press, 2008:50. [http://dx.doi.org/10.1155/rerp]

9. Kee D, Seo SR. Musculoskeletal disorders among nursing personnel in Korea. Int J Ind Ergon 2007;37(3):207-212. [http://dx.doi.org/10.1016/j.ergon.2006.10.020]

10. Van Heerden HJ. Pre-participation evaluation and identification of aetiological risk factors in epidemiology of sports injuries among youths. DPhil thesis. Pretoria: University of Pretoria, 1996.

11. Hagglund M, Walden M, Bahr R, Ekstrand J. Methods for epidemiological study of injuries to professional football players: Developing the UEFA model. Br J Sports Med 2005;39(6):340-346.

12. Finn JA, Alvarez MM, Jett RE, Axtell RS, Kemler DS. Stability performance assessment among subjects of disparate balancing abilities. Med Sci Sports Exerc 1999;31(5):S252. [http://dx.doi.org/10.1097/00005768199905001-01209]

13. Jerosch J. The influence of orthoses on proprioception of the ankle joint. Knee Surg Sports Traumatol Arthrosc 1995;3(1):39-46.

14. Bocchinfuso C, Sitler MR, Kimura IF. Effects of 2 semirigid prophylactic ankle stabilizers on speed, agility and vertical jump. J Sport Rehabil 1994;3(2):125-134

15. Gross MT, Bradshaw MK, Ventry LC, Weller KH. Comparison of support provided by ankle taping and semi-rigid orthosis. J Orthop Sports Phys Ther 1987;9(1):33-39. 